\title{
Performance and Tracking Control of Three-Phase Induction-Motor Drive Fed from a DC-Modified Nano-grid
}

\author{
ESSAMUDIN ALI EBRAHIM, ABUELMAATY M. ALI \\ Power Electronics and Energy Conversion Department, \\ Electronics Research Institute, \\ Joseph Tito St., Huckstep, Qism El-Nozha, Cairo Governorate, \\ Cairo, EGYPT
}

\begin{abstract}
Nowadays, induction motor (IM) can be used in tracking systems to follow a predefined path like in robotics and servos. The modified nanogrid is a small scalable-renewable energy intermittent source that powers loads via a single-stage inverter (SSI). Higher utilization of the inverter dc-link voltage improves its output voltage and dependently, the performance of the motor tracking speed. So, this paper proposed a switched boost inverter (SBI) to feed IM from PV-source to boost its dc-link output voltage. The usage SBI utilizes minimum passive components, more active elements, introduces shot-through mode as z-source inverter and produces both ac and dc voltages simultaneously. The performance of the motor-tracking speed depends directly on the motor- stator voltage. So, the proposed method depends mainly on two parameters to verify the pre-defined trajectory speed. The first proposed intention is a simple algorithm for a closed-loop dc-link boosting control based-on the reference model to compute the optimum duty ratio (D). The second one depends mainly on the modulation index (M) to produce the reference signals needed to adjust the speed of the motor through a (voltage/frequency) control of a predefined value. The modelling and validation of the proposed system was implicit with the help of Matlab/ Simulink package. The robustness of the system has been tested by selecting several speed trajectories and was able to track them. Furthermore, SBI-based system was compared with other VSI-inverter techniques such as the space-vector PWM single- and two-stage VSI inverters. Test results explored that the SBI-based system is a strong competitor to other inverter techniques especially at low-voltage intermittent supply.
\end{abstract}

Key-Words: - Induction motor Drive (IM), Photo-voltaic (PV), Switched Boost Inverter (SBI), Modified Nanogrid, Tracking Control

Received: September 8, 2020. Revised: February 26, 2021. Accepted: March 1, 2021. Published: March 3, 2021.

\section{Introduction}

Induction motors (IMs) are robust, inexpensive, require approximately no maintenance, and have a high power/ weight ratio [1-4]. Voltage and current source inverters (VSI and CSI) are used in adjustable speed drives of IMs [5-7]. Unfortunately, both of them have some limitations. When VSI upper switches or lower switches are turned on simultaneously, a zero state is produced. This means that a short circuit occurs through the VSI-output terminals. This short circuit is called shot-through short circuit. This shot-through is forbidden for each limb of 3-phases for VSI and can destroy all inverter modules. To prevent this overlap which causes this shot-through it should be using a dead-time delay circuit through the triggering process of electronic switches. Classical nanogrid with small rate uses both converter and inverter as a two-stage power converter [8]. Also, the two stage conversion system has drawbacks such that: the conventional hbridge inverter must provide the output voltage less than the input voltage, and its output cannot be more than the DC-link voltage [9-11]. So, a modified DC nanogrid is introduced to enhance the system operation. The structure of the modified nanogrid proposes a single stage boost inverter (SSBI) with reduced number of conversion systems between the photovoltaic (PV) and nanogrid with residential applications for both AC and DC loads [12,13]. Recent researches proposed Z- source inverter as a single input multi output (SIMO) inverter $[14,15]$. But, it needs to many reactive components and small number of active switches compared with the other single stage switched boost inverter which leads to increase the system cost, losses and decreases the system efficiency. Some efforts were exerted to improve the performance of Z-source inverter and overcame its defects such as in [16]. A novel power converter called switched boost inverter (SBI) is an 
improved copy of ZSI that demonstrates the same features of the z-inverter with using a few number of passive elements. The main features of a SBI that it allows the shot-through and no need to dead-time circuits. Also, it produces both ac and $\mathrm{dc}$ simultaneously. So, it can increase its an ac-output voltage to a sufficient value [17-22]. Although the features of SBI, but a few number of researches suggested using SBI with 3-phase IM drives such as in $[23,24]$. These researches discussed open-loop speed control of IM when feeding it via a SBI. There are rarely researchers that discussed the performance and behaviour of the IM - as a high performance drive- when feed from PV via a SBI. Also, some relevant studies can be found in [25] and [26].

So, this manuscript proposes a simple controller for a 3-phase IM-drive fed from a modified nanogrid with PV array- as a renewable resource - via SBI. The drive is an adjustable-speed highperformance tracking system that can follow a prescribed trajectory for the motor speed. The proposed controller is a simple algorithm to control the dc-link output voltage of SBI-capacitor to be robust against PV-parameters changes such as insolation and temperature. The proposed control technique depends on the combination of both modulation index $(M)$ and duty ratio $(D)$ for SBI. By controlling $D$, it can achieve maximum power-point tracking (MPPT) and maintain the DC-link output voltage and current of the inverter within the limited values. By using adjustable both voltage and frequency with the same rate to maintain the torque of the motor constant, it can generate the 3-phase sinusoidal reference voltage that can be compared with the carrier wave to obtain the triggering pulses of SBI. The value of $M$ varies from zero to 1 and gives a wide speed range for the motor. This helps in increasing the motor speed to reach the rated speed and contributes towards making IM as a highperformance drive. The robustness of the controller is tested by proposing several speed trajectories (such as trapezoidal, random, sinusoidal), and the motor succeeded to follow all of them. In addition, a comparison among space vector PWM 2-stage and 1stage VSI was conducted to prove the validity and suitability of the proposed drive in speed tracking. The organization of the paper is as follows: section 1 is an introduction, the proposed rig is introduced in section 2. Section 3 is a modified nano-grid with PVarray and SBI topology is explained in section 4 . The closed-loop control for dc-link voltage with MPPT is introduced in section 5. Section 6 is a validation for the proposed system through test results. Finally, the concluding remarks of the manuscript are given in section 7 .

\section{The Proposed Rig}

Figure 1 depicts the proposed system that implies the modified nano-grid with solar power as a renewable resource, 3-phase SBI, 3-phase IM, speed controller, feedback motor actual speed through speed-shaft encoder, three-phase voltage-reference control signals generation, ramp generation as a carrier signal, PWM-gating signals generation, and shot-through voltage level for DC-link voltage control. The mathematical model of IM was introduced in literature, so, the IM dq-model of this work obtained from $[3,4]$. Finally, the electrical mathematical model of induction motor can be expressed in matrix form as follows:

$$
\left[\begin{array}{c}
v_{d s} \\
v_{q s} \\
v_{d r}^{\prime} \\
v_{q r}^{\prime}
\end{array}\right]=\left[\begin{array}{cccc}
{\left[R_{s}+\frac{p}{\omega_{s b}} X_{1}\right]} & -\left(\frac{\omega_{b}}{\omega_{s b}} X_{1}\right) & \frac{p}{\omega_{s b}} X_{M} & -\left(\frac{\omega_{b}}{\omega_{s b}} X_{M}\right) \\
-\left(\frac{\omega_{b}}{\omega_{s b}} X_{1}\right) & {\left[R_{s}+\frac{p}{\omega_{s b}} X_{1}\right]} & \left(\frac{\omega_{b}}{\omega_{s b}} X_{M}\right) & \frac{p}{\omega_{s b}} X_{M} \\
\frac{p}{\omega_{s b}} X_{M} & -\left(\omega_{b}-\omega_{r}\right) \cdot \frac{X_{M}}{\omega_{s b}} & {\left[R_{r}^{\prime}+\frac{p}{\omega_{s b}} X_{2}^{\prime}\right]} & -\left(\omega_{b}-\omega_{r}\right) \cdot \frac{X_{2}^{\prime}}{\omega_{s b}} \\
\left(\omega_{b}-\omega_{r}\right) \cdot \frac{X_{M}}{\omega_{s b}} & \frac{p}{\omega_{s b}} X_{M} & \left(\omega_{b}-\omega_{r}\right) \cdot \frac{X_{2}^{\prime}}{\omega_{s b}} & {\left[R_{r}^{\prime}+\frac{p}{\omega_{s b}} X_{2}^{\prime}\right]}
\end{array}\right]\left[\begin{array}{c}
i_{d s} \\
i_{q s} \\
i_{d r} \\
i_{q r}
\end{array}\right](1)
$$

And the mathematical model for the mechanical part is: $T_{e}=J \frac{d \omega_{m}}{d t}+B \omega_{m}+T_{l}$

\subsection{Variable-Voltage Variable-Frequency (Scalar Speed Control)}

Figure 2 represents the block diagram for variable-voltage variable-frequency PI-speed controller. The error signal is the difference between both actual and reference rotor speed in the form of frequency according to the relation:

$$
\begin{aligned}
& f=\frac{P N}{60} \\
& e(t)=\left(f_{r}^{*}-f_{r}\right)
\end{aligned}
$$

Where $\mathrm{P}$ is the number of pair-poles, $f_{r}^{*}, f_{r}$ is the rotor reference and actual frequency and $e$ is the error signal. The output of the PI-controller is the slipfrequency $f_{\text {slip }}$ :

$$
\begin{aligned}
f_{\text {slip }} & =K_{p} \cdot e(t)+K_{i} \int e(t) d t \\
& =K_{p} \cdot\left(f_{r}^{*}-f_{r}\right)+K_{i} \int\left(f_{r}^{*}-f_{r}\right) d t
\end{aligned}
$$

Then, the reference synchronous frequency $f_{S}^{*}$ of the motor can be computed as:

$$
f_{s}^{*}=f_{r}+f_{\text {slip }}
$$

To maintain the internal torque constant, the stator voltage should be changed with the same rate of frequency changing, so the reference voltage peak- 


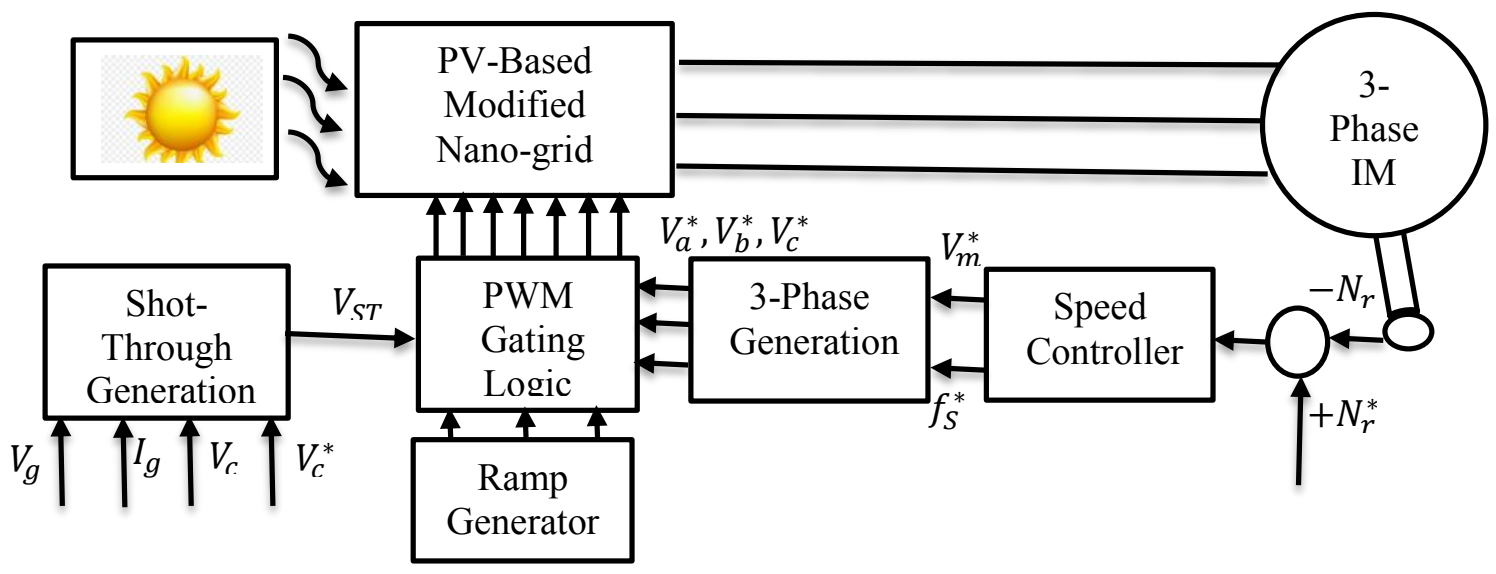

Figure 1. The proposed system

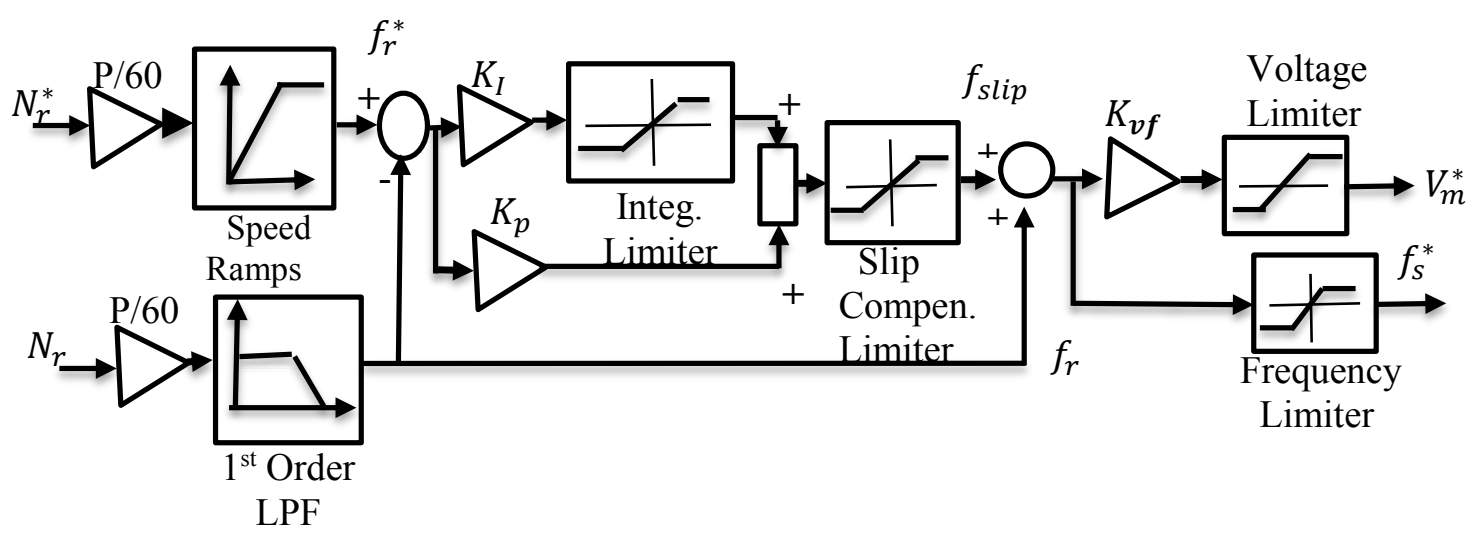

Figure 2 Block diagram for the speed controller (scalar controller $V / f$ )

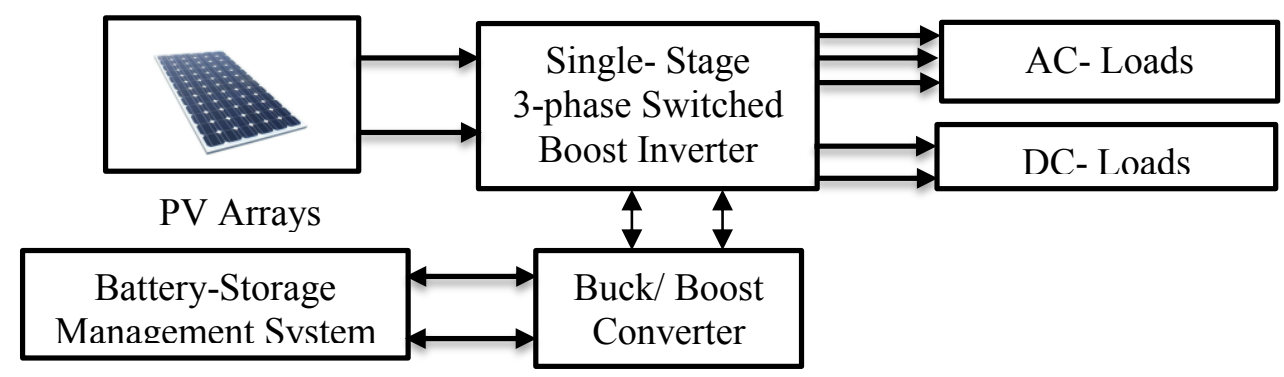

Figure 3. PV- based modified nanogrid

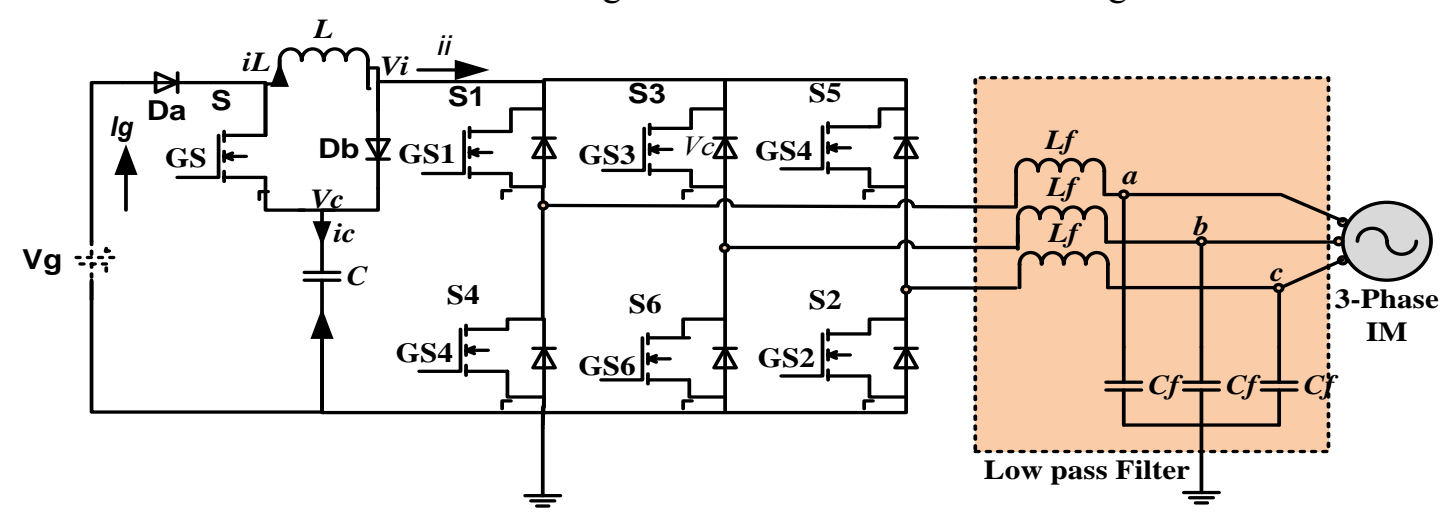

Figure 4 Schematic diagram of switched boost inverter fed 3-phase IM 

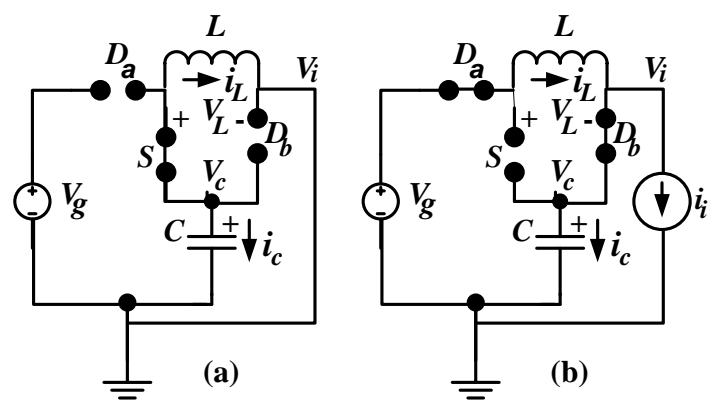

Figure 5 Equivalent circuit of SBI through interval

$$
\text { (a) } D . T_{s} \text { (b) }\left(1-D . T_{s}\right)
$$

value $V_{m}^{*}$ can be scaled with frequency according to the relation: $V_{m}^{*}=K_{v f} \cdot f_{s}^{*}$

Where, $K_{v f}$ is a constant depends on flux and selected according to the rated frequency and voltage of the machine. For this work, this value is equal 3.2 for the test machine.

\section{PV-Based Modified Autonomous Nano- grid}

The modified nanogrid consists of renewable energy resource such as PV-array, singlestage inverter such as SBI, storage management system such as batteries, and buck-boost converter as shown in figure 3. This study will focus only on the PV-array model and 3-phase SBI topology. Only, 3phase IM is considered as an ac load.

\subsection{Mathematical Model of PV-Array}

Several parameters and aspects are affected on the output power generated by the PV modules. Some of these significant factors are: PV-material type, intensity of solar insolation received by the module, module temperature, parasitic resistances, shading and cloud effect, dust, module location, weather, module orientation, cable resistances, and the efficiency of the inverter. The output is directly proportional to the intensity of solar insolation and inversely proportional to the temperature [27].

Moreover, several mathematical models of the PV module are proposed for simulation. The accurate model is used in this work. It takes into consideration the series and shunt resistances. The cell current is given as follows:

$$
I=I_{i r r}-I_{o}\left[e^{\left(\frac{q\left(V+I R_{S}\right)}{n k T}\right)}-1\right]-\frac{V+I R_{S}}{R_{p}}
$$

Then, the current of the module is given as:

$$
I_{M}=I_{\text {irr }}-I_{O}\left[e^{\left(\frac{q\left(V_{M}+I_{M} N_{S} R_{S}\right)}{N_{S} n k T}\right)}-1\right]-\frac{V_{M}+I_{M} N_{S} R_{S}}{N_{S} R_{p}}
$$

The array model includes several series and parallel modules [28-29]. In an array, PV modules are connected in series and in parallel. The array current $I_{g}$, terminal voltage $V_{g}$ and has $N_{S}$ cells in series and $N_{P}$ strings in parallel can compute all by using the following equation [30]:

The PV-array current is:

$$
\begin{gathered}
I_{g}=N_{p} I_{i r r}-I_{o}\left[e^{\left(\frac{q\left(V_{g}+I_{A} \frac{N_{S}}{N_{p}} R_{S}\right)}{N_{S} n k T}\right)}-1\right]- \\
\frac{V_{g}+I_{A}\left(\frac{N_{S}}{N_{p}}\right) R_{S}}{\frac{N_{S}}{N_{p}} R_{p}} \\
V_{g}=\frac{N_{S}}{\Lambda} \ln \left[\frac{G N_{P} I_{p v}-I_{i r r}}{N_{p} I_{o}}+1\right]-\frac{N_{S}}{N_{p}} R_{S} I_{g} \\
\text { And } \Lambda=\frac{q}{\epsilon K T}
\end{gathered}
$$

Also, the total output of the PV array can be determined as:

$P_{g}=V_{g} \times I_{g}$

Where, $P_{g}$ is the mean power of the array in (W), $I, I_{g}$ module and array currents in (A), $I_{i r r}$ is the current of irradiance (A), $I_{o}$ is the saturation current of diode (A), $V_{M}, V_{p v}$ are the module and array voltages (V), $q=1.6 \times 10^{-19} C$ is the electron charge in (C), $K=$ Boltzmann constant and equal $1.3806503 \times 10^{-23} \mathrm{~J} / \mathrm{K}, \quad R_{s}, R_{p}$ are series and parallel resistances $(\Omega), N_{s}$ and $N_{p}$ are number of series and parallel cells, $T=298.15$ is the temperature of the cell $\left({ }^{\circ} \mathrm{K}\right), \epsilon=1.1$ is the completion factor, $\Lambda$ is the solar cell constant, $G$ is the solar insulation in per unit.

\section{The Proposed Switched Boost Inverter (SBI) Topology}

SBI - as shown in figure (4) - it consists of two diodes, one inductor, one capacitor, 7-IGBTs, and an L-C passive filter for harmonic mitigation. As the ZSI, it utilizes the shoot-through state of the inverter to boost its output voltage $V_{C}$. The shot-through zerostate is assumed to be acted through the interval $\left(D . T_{S}\right)$ and the mathematical equation of SBI through this period can be obtained - with the help of its equivalent circuit shown in figure (5) (a) and (b)- as follows [31]:

$v_{L}(t)=v_{C}(t), i_{C}(t)=-i_{L}(t), v_{i}(t)=0$

But, through the interval $\left.\left((1-D) . T_{S}\right)\right)$, the equation of the model is given as:

$v_{L}(t)=V_{g}-v_{C}(t), \quad i_{C}(t)=i_{L}(t)-i_{i}(t)$,
$v_{i}(t)=v_{C}(t)$

During the interval $T_{S}$, the average voltage across $\mathrm{L}$ equal to zero, then:

$$
\frac{V_{C}}{V_{g}}=\frac{1-D}{1-2 D}
$$




\subsection{The Proposed Intension Modulation-Index Speed Control}

As seen from equation 15 and similar to ZSI, the duty ratio $(D)$ of SBI is limited from 0 to 0.5 . Also, the relation between modulation index $M$ and $D$ is determined according to the following criteria:

$$
M+D \leq 1
$$

The maximum peak value for ac-output voltage for the line can be determined as:

$$
V_{m}=M V_{C}=\frac{(1-D) M V_{g}}{(1-2 D)}
$$

Then, the three-phases output voltages that supply the motor are:

$V_{a s}=V_{m} \sin (w t), \quad V_{b s}=V_{m} \sin (w t-2 \pi /$

$3), \quad V_{c s}=V_{m} \sin (w t+2 \pi / 3)$

By substituting in eqn. 18 from 17, it can be obtain the stator input voltage as a function of $M$ as follows:

$$
V_{a s}=\frac{(1-D) M V_{g}}{(1-2 D)} \sin (w t)
$$

Figure 6 explores the block diagram to generate the required control signals of SBI. Six signals are required for six-pulse switches and another one for shot-through. The reference signal is a sinusoidal that can be obtained from the two reference control signals. They can be computed as follow: $\omega_{s}=2 \pi f_{s}^{*}$ and $V_{m p}^{*}=V_{m}^{*} / V_{B} \quad$ where $V_{B}$ is the base value and equal to the rated voltage. Then 3-phase reference sinusoidal signals are:

$V_{a}^{*}=V_{m p}^{*} \sin \left(\omega_{s} t\right), \quad V_{b}^{*}=V_{m p}^{*} \sin \left(\omega_{s} t-\right.$

$2 \pi 3), \quad V_{c}^{*}=V_{m p}^{*} \sin \left(\omega_{s} t+2 \pi / 3\right)$

Figure 7 (a) shows the peak value for the triangular carrier wave $V_{p}$.

$$
V_{t r i}= \begin{cases}\frac{-V_{p}}{T_{s}}\left(t-\frac{T_{s}}{4}\right) & \text { if } 0<t<\frac{T_{s}}{4} \\ \frac{V_{p}}{T_{s} / 4}\left(t-\frac{3 T_{s}}{4}\right) & \text { if } \frac{T_{s}}{2}<t<T_{s}\end{cases}
$$

Where, $T_{S}$ is the switching time for carrier wave and $f_{s}$ is the switching frequency of SBI.
And the shot-through modulated signals $+V_{S T}$ and $V_{S T}$ - shown in figure $7 \mathrm{~b}$ - can be computed as:

$+V_{S T}=V_{p}(1-D),-V_{S T}=-V_{p}(1-D)$

\subsubsection{Generation of gating control signals} $\left(G_{s 1}, G_{s 3}, G_{s 5}\right)$ of $S B I$

The complete cycle for the modulation sinusoidal wave form is divided to four intervals as shown in Table 1 and demonstrated in figure 7 (b). The state (high or low) for each interval depends on the value of the modulation signal to the carrier wave. Table one shows only the low state condition for switches $\left(G_{s 1}, G_{s 3}, G_{s 5}\right)$. The high state will be achieved when all conditions in this table are not satisfied.

\subsubsection{Generation of gating control signals $\left(G_{s 2}, G_{s 4}, G_{s 6}\right)$ of $S B I$}

In traditional VSI, the control gating pulses for lower switches are the complementary to upper switches. But, this is not true for SBI. Table 2 also describes the four intervals and conditions to generate (high/low) states for the lower switches.

\subsubsection{Generation of gating control signal $\left(G_{S}\right)$ of SBI}

Switch $\mathrm{S}$ is turned on in shot-through period. And it will be turned off when it is in non-shot through state. The non-shot-through state can be achieved when all control signals for each leg of the inverter are complementary to others. However, $G_{S}$ is generated when $-V_{S T}<V_{t r i}<+V_{S T}$. For more details, it can be referred to ref. [31].

The modulation index can be computed from the following relation:

$$
M=\frac{V_{m p}^{*}}{V_{P}}
$$

By substituting from eqn. (3) and (7) in (22),

$M=\frac{V_{m p}^{*}}{V_{P}}=K_{v f} \cdot \frac{f_{s}^{*}}{V_{P}}=K_{v f} \cdot \frac{P N}{60 . V_{P}}$

From (23), $M$ is directly proportional to speed, where, $V_{P}, K_{v f}$, and $P$ are constant. Then, it can substituting in eqn. (19) as:

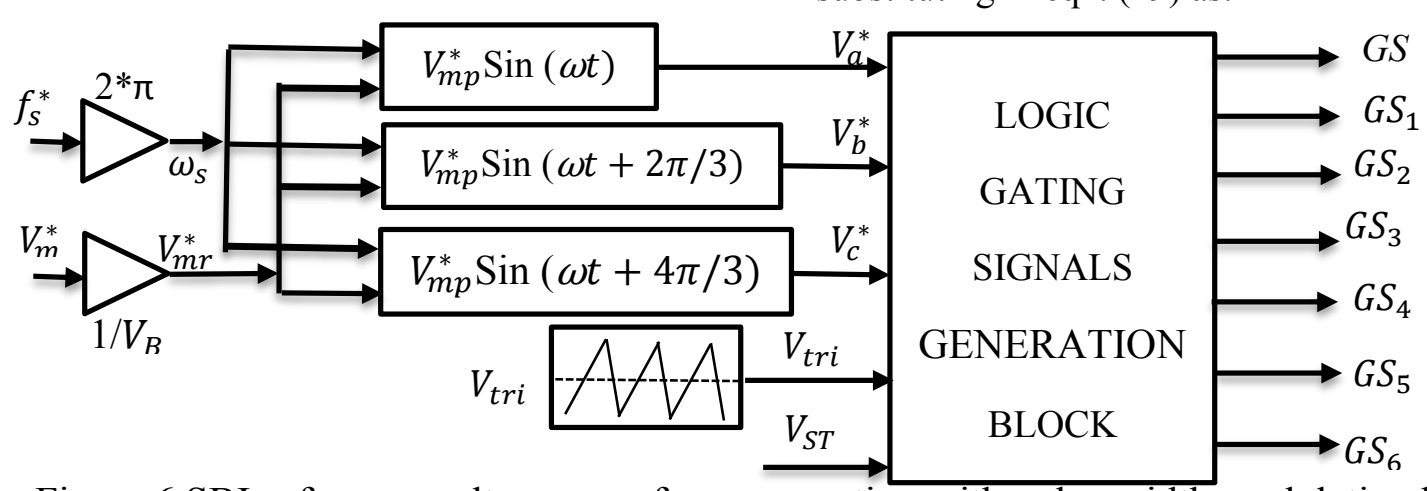

Figure 6 SBI-reference voltage waveform generation with pulse-width modulation block 
Table 1. Gate control signal generation for $S_{1}, S_{3}, S_{5}$

\begin{tabular}{|c|c|c|c|c|}
\hline Interval & Value of & \multicolumn{3}{|c|}{ Condition for gate control signal to be low } \\
\cline { 3 - 5 } No. & $\omega t$ & $G_{S 1}$ & $G_{S 3}$ & $G_{S 5}$ \\
\hline 1 & $0^{\circ}-90^{\circ}$ & $V_{a}^{*}<V_{t r i}$ & $V_{b}^{*}<V_{t r i}<V_{S T}$ & $V_{c}^{*}<V_{t r i}$ \\
\hline 2 & $90^{\circ}-210^{\circ}$ & $V_{a}^{*}<V_{t r i}$ & $V_{b}^{*}<V_{t r i}$ & $V_{c}^{*}<V_{t r i}<V_{S T}$ \\
\hline 3 & $210^{\circ}-330^{\circ}$ & $V_{a}^{*}<V_{t r i}<V_{S T}$ & $V_{b}^{*}<V_{t r i}$ & $V_{c}^{*}<V_{t r i}$ \\
\hline 4 & $330^{\circ}-360^{\circ}$ & $V_{a}^{*}<V_{t r i}$ & $V_{b}^{*}<V_{t r i}<V_{S T}$ & $V_{c}^{*}<V_{t r i}$ \\
\hline
\end{tabular}

Table 2. Gate control signal generation for $S_{2}, S_{4}, S_{6}$

\begin{tabular}{|c|c|c|c|c|}
\hline Interval & Value of & \multicolumn{3}{|c|}{ Condition for gate control signal to be low } \\
\cline { 3 - 5 } No & $\omega t$ & $G_{s 1}$ & $G_{s 3}$ & $G_{s 5}$ \\
\hline 1 & $0^{\circ}-30^{\circ}$ & $V_{a}^{*}>V_{t r i}$ & $V_{b}^{*}>V_{t r i}$ & $V_{c}^{*}>V_{t r i}>-V_{S T}$ \\
\hline 2 & $30^{\circ}-150^{\circ}$ & $V_{a}^{*}>V_{t r i}>-V_{S T}$ & $V_{b}^{*}>V_{t r i}$ & $V_{c}^{*}>V_{t r i}$ \\
\hline 3 & $150^{\circ}-270^{\circ}$ & $V_{a}^{*}>V_{t r i}$ & $V_{b}^{*}>V_{t r i}>-V_{S T}$ & $V_{c}^{*}<V_{t r i}$ \\
\hline 4 & $270^{\circ}-360^{\circ}$ & $V_{a}^{*}>V_{t r i}$ & $V_{b}^{*}>V_{t r i}$ & $V_{c}^{*}>V_{t r i}>-V_{S T}$ \\
\hline
\end{tabular}
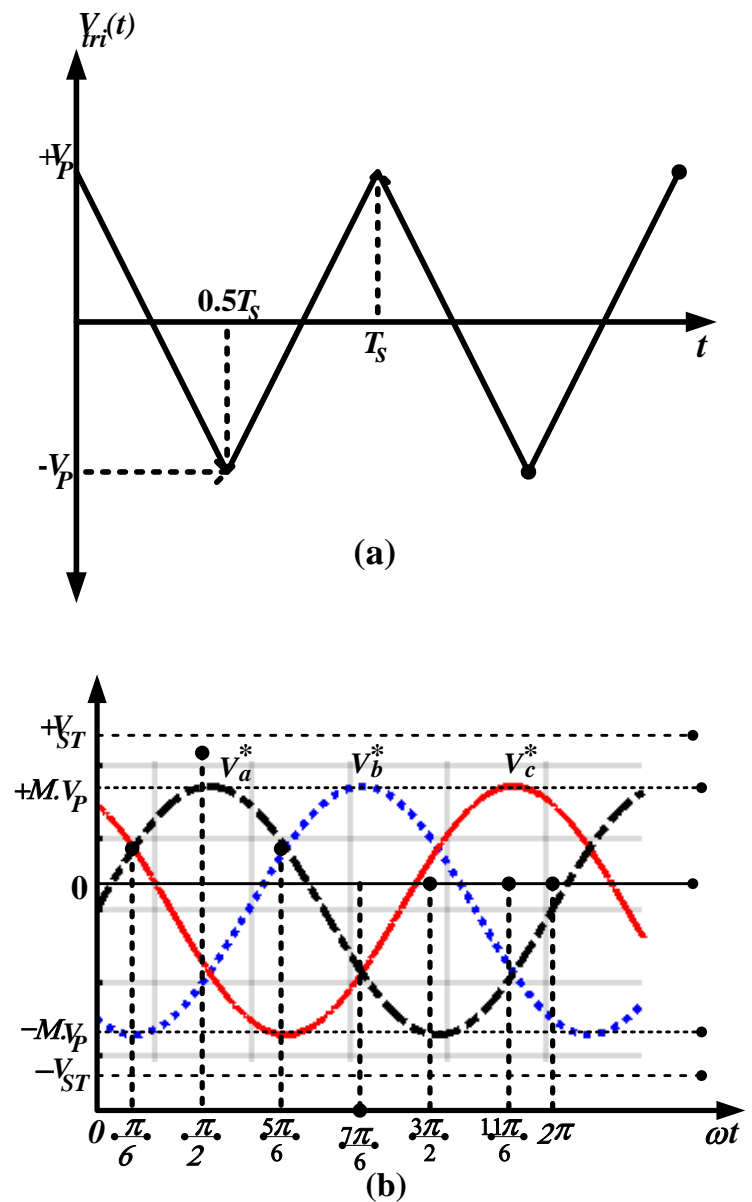

Fig. 7 (a) Triangular carrier signal (b) The five modulation signals $\left(+V_{S T},-V_{S T}, V_{a}^{*}, V_{b}^{*}, V_{c}^{*}\right)$

$V_{a s}=\frac{K_{v f}(1-D) \cdot P N V_{g}}{60 * V_{P^{*}}(1-2 D)} \sin (w t)$, this means that the speed of the motor also depends on the duty ratio $D$ and should be controlled to give a wide speed range.

\section{Proposed Closed-Loop DC-Link Voltage Control \\ 5.1. Maximum Power Point Tracking (MPPT) Algorithm}

There are several proposed techniques for maximum power point (MPP) operation as in [32]. However, this study uses incremental conductance method - as a simple algorithm - to determine MPPT [33]:

$\frac{d P_{g}}{d V_{g}}=\frac{d\left(V_{g} I_{g}\right)}{d V_{g}}=I_{g}+V_{g} \frac{d I_{g}}{d V_{g}}=0$

By approximately linearizing the relationship of grid current by substituting from (10) and (11) in (24):

$I_{g}=I_{M P P} \cong 0.94 I_{s c}$

Where, $I_{M P P}$ is the array output current at a MPP and $I_{S C}$ is a short circuit current for the PV array.

By integrating the eqn. (24) to minimize the error, this gives the duty ratio that achieves MPPT $\left(D_{m p p}\right)$ as:

$D_{m p p}=\int K_{m}\left(\frac{I_{g}}{V_{g}}+\frac{d I_{g}}{d V_{g}}\right) d t+D_{0}$

\subsection{The Proposed Model as a Reference for DC-Link Voltage Control}

Figure 8 depicts the block diagram for both voltage and current control, this block produces the voltage level control signal $\left(V_{S T}\right)$ that is needed for shot-through signals controlling the switch $(S)$.

The control algorithm depends on introducing a mathematical model for the actual value of $V_{S T}$ that can be computed as follows [34]:

From eqn. $21, D=1-\frac{V_{S T}}{V_{P}}$

If $V_{P}=2$, by substituting in eqn. 27 ,

$D=1-\frac{V_{S T}}{2}$

By substituting in eqn. 15 from 28 , 


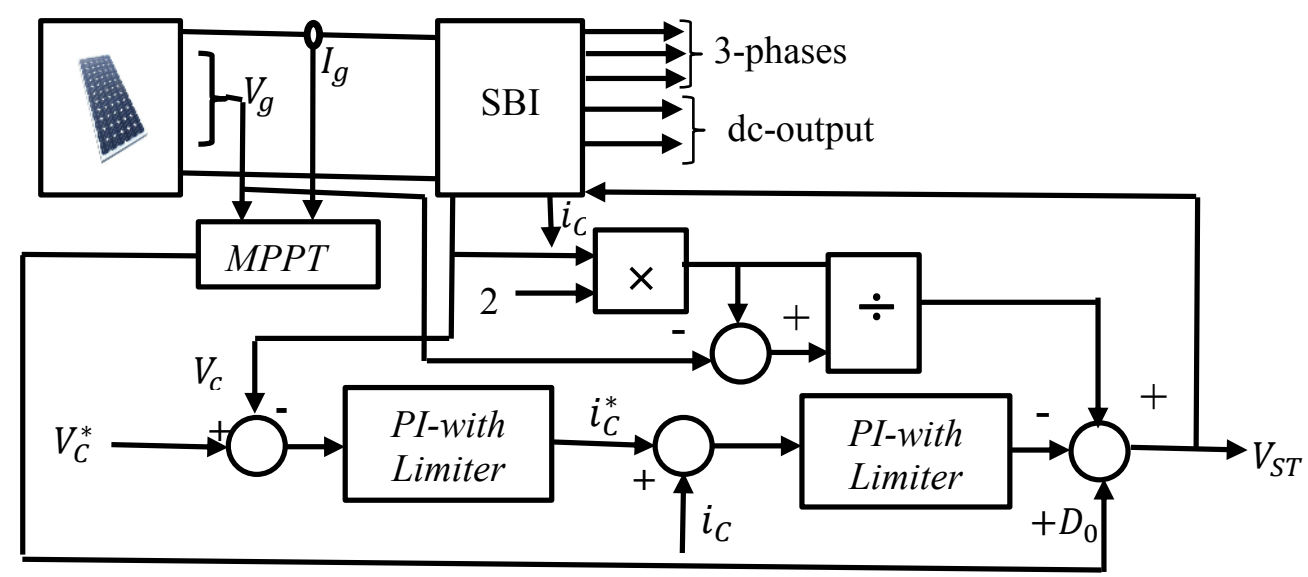

Figure 8 Block diagram for model-reference of dc-link output voltage closed-loop control

$$
V_{S T}=\frac{2 * V_{C}}{2 * V_{C}-V_{g}}
$$

From equation (29), the block diagram for this model is drawn as a reference and its output is added to the output of the PI-controllers used for both voltage and current as shown in figure 7 . The error signals for both dc-link voltage and current are:

$e_{v}=V_{C}^{*}-V_{C}$ and $e_{i}=i_{C}^{*}-i_{C}$

The values of controller gains $K_{p}, K_{i}$ are selected with very small values to use this term as a fine tuning for the output of the system. In addition, the final term obtained from Equ. (26) - is also added to the final block to balance between achieving both MPPT and voltage stability of the DC link.

\section{TEST RESULTS AND DISCUSSION}

To test the robustness of the proposed system with the IM as a high performance drive, a software package is introduced with the help of Matlab/Simulink program. The main data of 1-hp 3phase IM as a test machine is included in Tab. 3. This data was obtained from references [1] and [2]. Also, the main parameters of the SBI are also modelled and implied in Tab. 4. The data of this table was collected from these references [23],[24],[31] and [34]. In this study, several speed trajectories are proposed for a wide speed range to test the robust of the proposed controller with SBI. Also, these proposed trajectories include an acceleration, deceleration, 2-quadrant operation of the motor. In addition, results include the PV-variable profiles with time such as irradiation, the output voltage $V_{g}$, power $P_{g}$, and some control signals such as modulation 3-phase reference signals $V^{*}$, and triangular signal $V_{t r i}$. Four cases are studied. All results for each case include dependently other parameters variation such as motor and load torque, stator current and dc-link voltage of the inverter.

All cases including the same proposed irradiance profile shown in figure (9-a) to test the robustness of the controller against PV-parameter variations.

The gain values for speed-controller are selected as $K_{p}=5, K_{i}=12$ for all trajectories. Also, these values for dc-link voltage proposed controller are $K_{p}=.00001, K_{i}=0.00005$ for both voltage and current loops with limiting block value $\mp 2$.

Table 3. The name plate data of the test machine

\begin{tabular}{|c|c|c|}
\hline parameter & value & unit \\
\hline Rated voltage & 220 & $\mathrm{~V}$ \\
\hline Rated power & 1 & $\mathrm{hp}$ \\
\hline Rated frequency & 50 & $\mathrm{~Hz}$ \\
\hline Rated line current & 2.3 & $\mathrm{~A}$ \\
\hline Rated speed & 960 & $\mathrm{Rpm}$ \\
\hline No. of pair poles $(P)$ & 3 & poles \\
\hline Stator resistance $\left(R_{s}\right)$ & 10.5 & $\Omega$ \\
\hline $\begin{array}{c}\text { Rotor resistance referred to stator } \\
\left(R_{r}^{\prime}\right)\end{array}$ & 11.08 & $\Omega$ \\
\hline Stator leakage reactance $\left(X_{l s}\right)$ & 11.03 & $\Omega$ \\
\hline $\begin{array}{c}\text { Rotor leakage reactance referred to } \\
\text { stator }\left(X_{l r}\right)\end{array}$ & 11.03 & $\Omega$ \\
\hline Magnetizing Reactance $\left(X_{m}\right)$ & 126.3 & $\Omega$ \\
\hline Rotor moment of inertia & .042 & $\mathrm{Kg} . \mathrm{m}^{2}$ \\
\hline
\end{tabular}

Table 4. The values of SBI parameters

\begin{tabular}{|c|c|c|}
\hline parameter & value & unit \\
\hline Grid-input voltage $\left(V_{g}\right)$ & 255 & $\mathrm{~V}$ \\
\hline Limitation of DC-link voltage $\left(V_{C}^{*}\right)$ & 622 & $\mathrm{~V}$ \\
\hline Fundamental frequency $(f)$ & 50 & $\mathrm{~Hz}$ \\
\hline Switching Frequency $\left(f_{s w}\right)$ & 10 & $\mathrm{kHz}$ \\
\hline Inductance of main inductor $(L)$ & 5 & $\mathrm{mH}$ \\
\hline Capacitance of main capacitor $(C)$ & 1500 & $\mu \mathrm{F}$ \\
\hline Inductance of filter inductor $\left(L_{f}\right)$ & 1 & $\mathrm{mH}$ \\
\hline Capacitance of filter capacitor $\left(C_{f}\right)$ & 150 & $u F$ \\
\hline
\end{tabular}



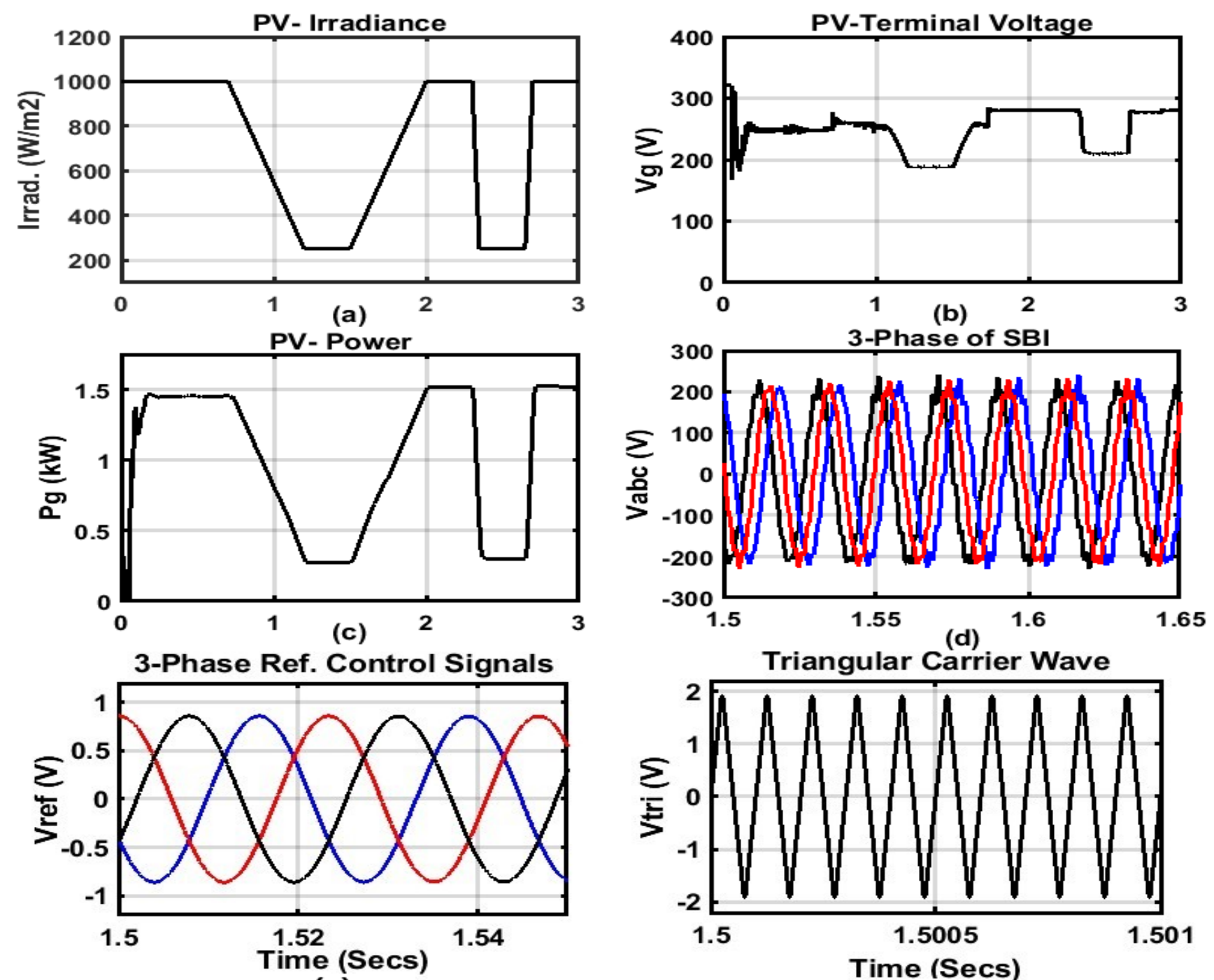

(e)

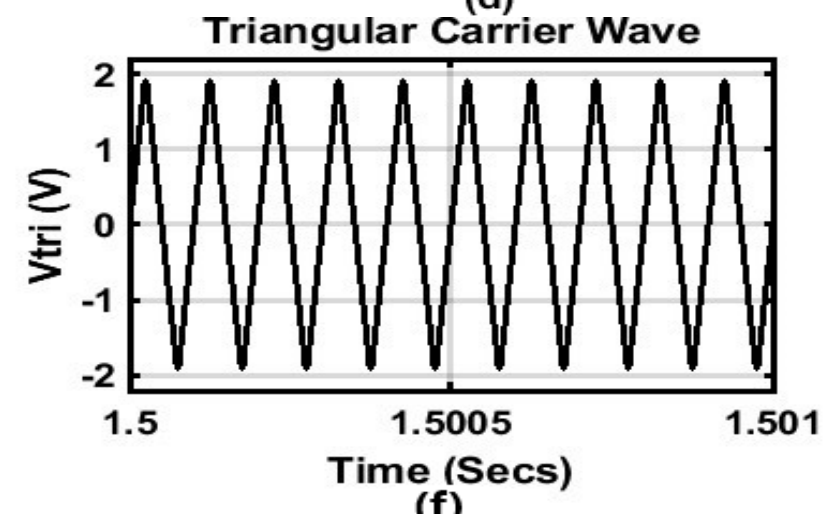

Fig. 9 (a) PV-irradiance (b) PV-terminal voltage (c) PV-mean power (d) 3-phase SBI voltage (e) 3-phase reference signals (f) carrier wave

The selected module for the solar panel and its technical specification is given in appendix A. The module specifications were extracted from NREL System Advisor Model (website [35]). Its type model is Sunpower SPR-305-WHT-U (305W) Solar Panel. The PV array consists of 5 modules all connected in series to give approximately $1.5 \mathrm{~kW}$ at $270 \mathrm{~V}$ or connected in parallel to give $54 \mathrm{~V}$. SBI has many advantages but the main drawback is its duty ratio is limited to 0.5 . So, the proposed control is used to overcome this defect, especially, though the instability region $(0.45$ to 0.5 ). Also, the main purpose of the controller is keeping the DC-link voltage of SBI constant with simultaneously MPP achievement. Keeping DC-link constant insures a perfect control for predetermined speed trajectories. Also, the modulation index contributes towards tracking the trajectory without deviation. So, both $D$ and $M$ profiles with time are plotted to show their variation effects through the speed trajectories. In addition, the test results imply a comparison between the proposed SBI and VSI with and without converter using space-vector PWM [36]. All parameters are the same for each system, i.e., the same speed controller gains, the same $(V / f)$ control technique with the same parameters. Through the results, the VSI- without converter is considered as a single-stage and denoted by (SVPWM-1) and with converter is a two-stage and denoted by (SVPWM2). Also, all cases are including variable load torque with time. Figures (9-b and c) demonstrate the PVoutput voltage and generated power according to the proposed insolation profile shown in fig. 8a. As shown, both of them affected by the irradiance variation. Also, figure (9-d) represents the threephase AC-output voltage for SBI - as a sample - for input to the stator. In addition, figures (9-e and f) are 
the 3-phase modulation and carrier waves used in pulse generation for IGBTs of SBI.

\subsection{Case (1): Trapezoidal Speed Trajectory}

In this case, the speed trajectory is a trapezoidal to test the acceleration and deceleration in forward rotation. The number of series panels are 5 to give approximately $1.5 \mathrm{~kW}$ solar power at around $270 \mathrm{~V}$ input to the SBI with the same insolation profile described in figure 8 -a. The steady state speed for the trajectory is the motor-rated speed (i.e., $960 \mathrm{rpm}$ ). Figure 10-a explores actual and reference trapezoidal speed trajectories. Through acceleration region, there is a slight difference between the reference and actual, then there is a matching between both with some oscillations at the nominal motor speed region and then some deviations through the deceleration. Figure 10-b describes the motor current through this track. Also, the motor and load torques are shown in
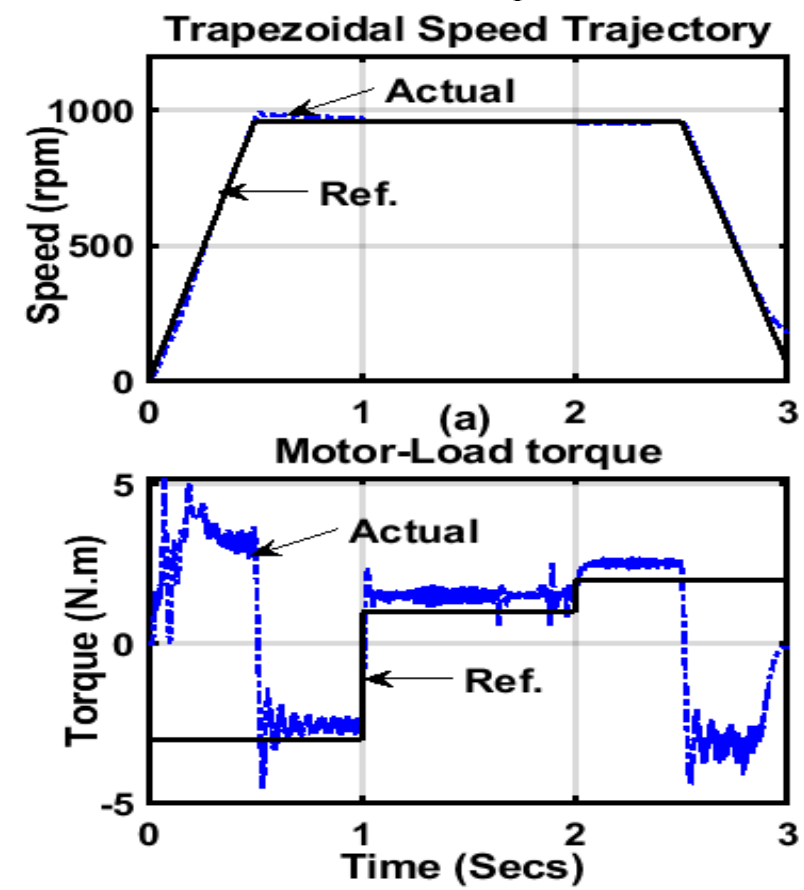

(c)

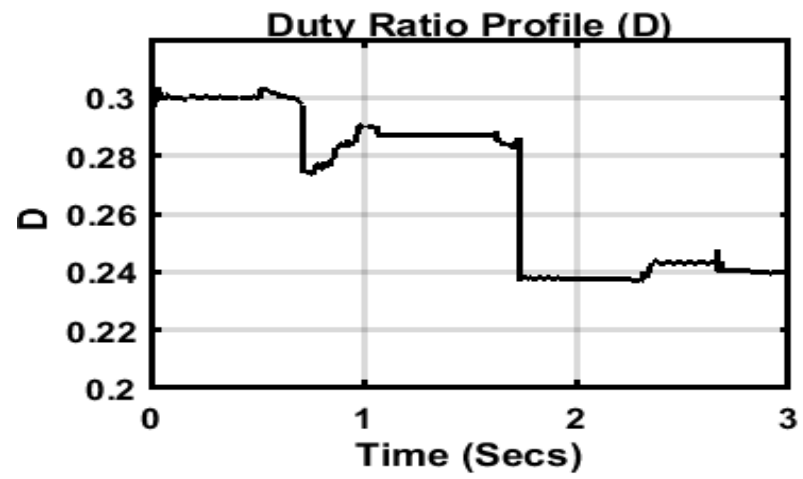

(e) figure 10-c. There is some oscillations and deviation between them through acceleration and deceleration. The dc-link voltage profile that contributes in tracking achievement is shown in figure 10-d. Although the insolation of the PV was reduced from 1000 to approximately $200 \mathrm{~W} / \mathrm{m}^{2}$ as shown in fig. 9a, but the proposed controller boosted the dc-link voltage to suitable tracking-speed values. When irradiation is low, the duty ratio decreases with the help of the proposed robust controller to increase the DC-link voltage and vice versa. When the insolation increases, the terminal voltage maintains constant by increasing duty ratio of the inverter. The profile of both $\mathrm{D}$ and $\mathrm{M}$ with time are illustrated in figures 10 (e) and (f) respectively. As shown, the D is decreased with the insolation reduction and vice versa. Also, $\mathrm{M}$ is directly proportional to the speed. M-profile is approximately the same as the speed trajectory with some oscillations through transient.
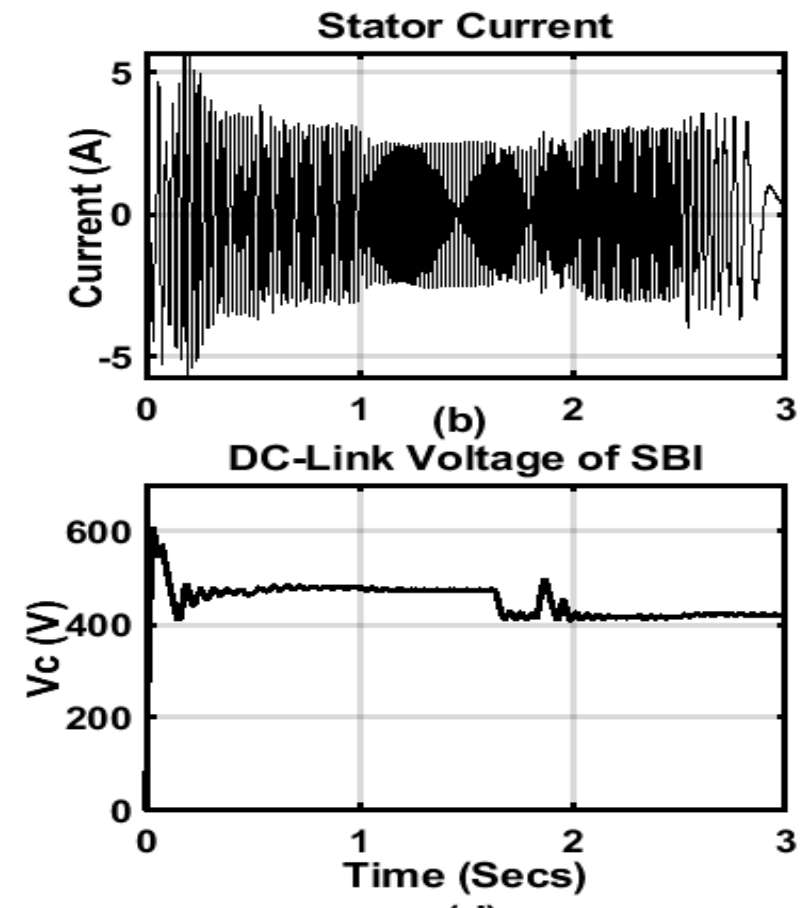

(d)

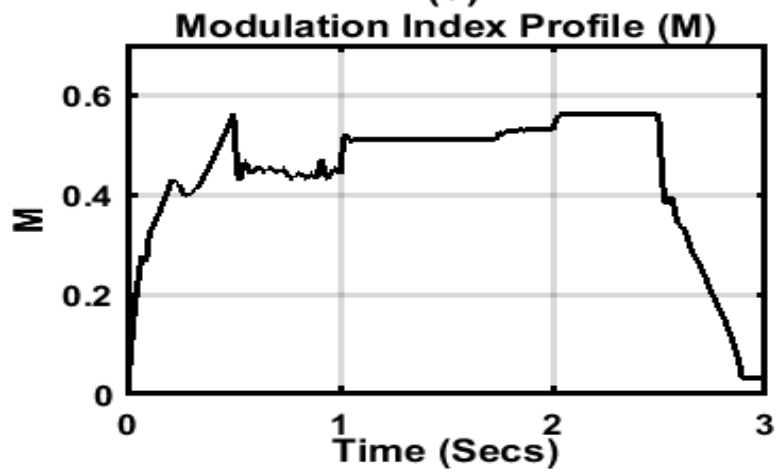

(f)

Fig. 10 Case 1: Trapezoidal speed trajectory (a) speed (b) current (c) torque (d) DC-link voltage of SBI (e) D-profile with time (f) M-profile with time 

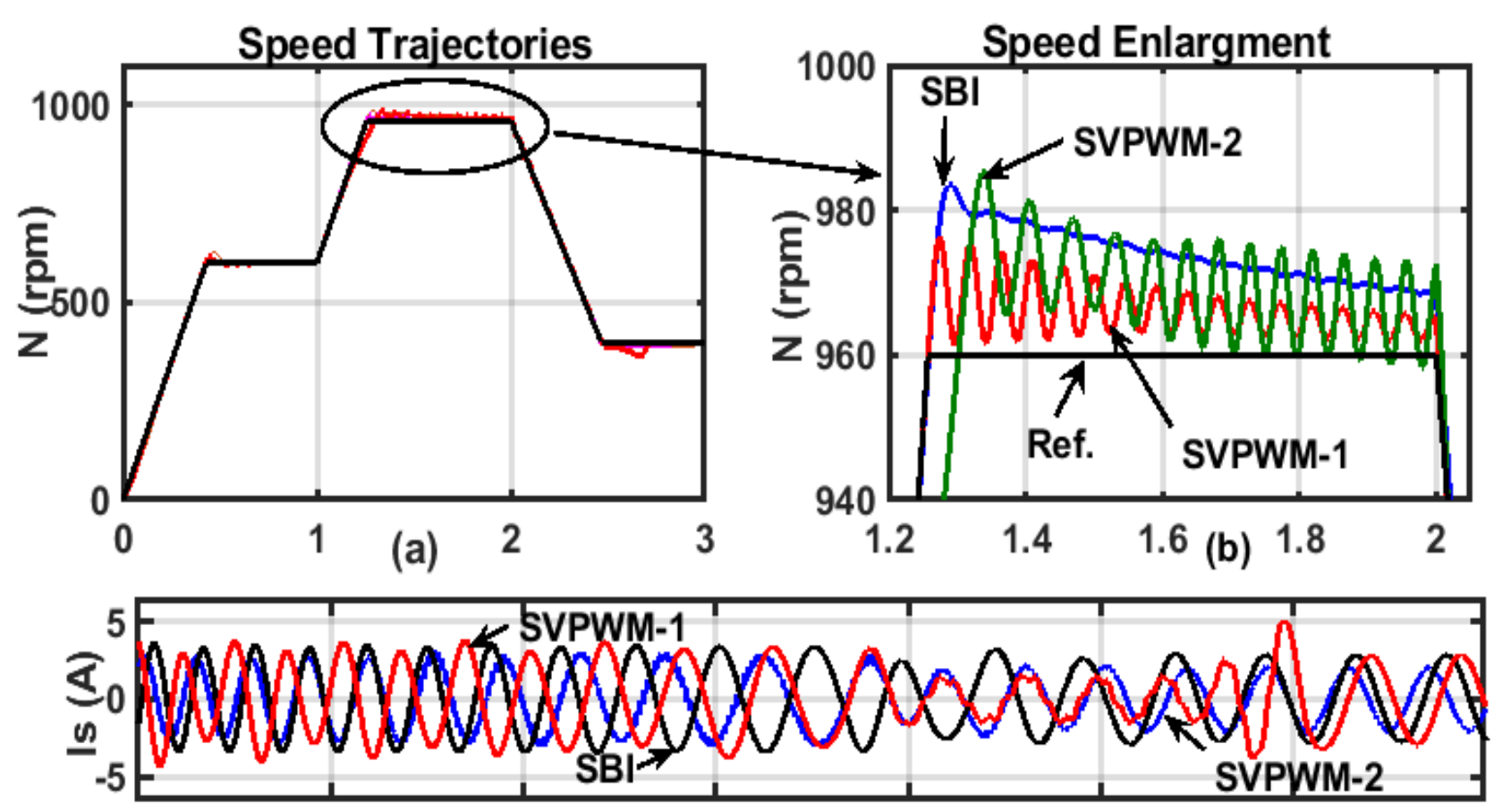
2.1
2.2
2.3
2.4
(c) 2.5
2.6
2.7
2.8

Motor \& load Torques

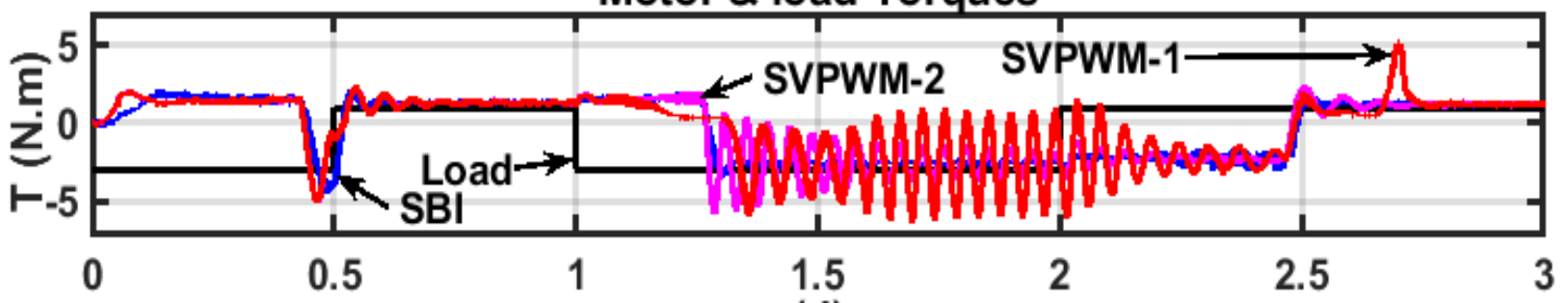

(d)

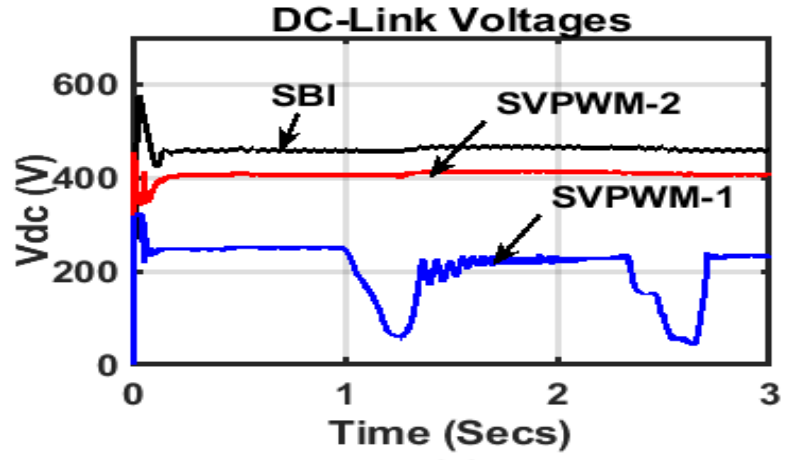

(e)

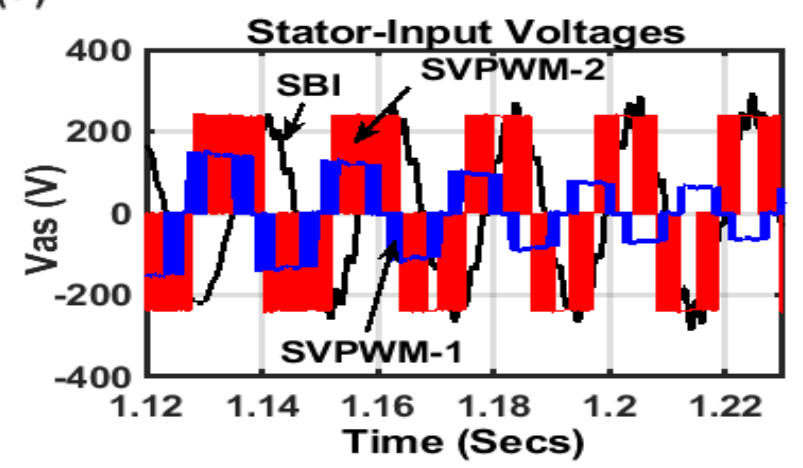

(f)

Fig. 11 Case 2: random trajectory with acceleration to rated-speed and deceleration (comparison)

(a) Speed (b) speed-enlargement (c) current (d) torque (e) dc-link voltage (f) stator input voltage

\subsection{Case (2): Random Forward Speed} Trajectory (with a Comparison)

In this case, the speed trajectory was selected randomly with including acceleration and sharpdeceleration in forward motor rotation. The same input voltage - as in case 1 - is used (i.e., $V_{g}=$ $270 \mathrm{~V})$. The motor is accelerated in steps from zero to $(600 \mathrm{rpm})$ and then raised to nominal speed. After that, the motor decelerated from rated speed to 400 rpm. The acceleration and deceleration act through very short period. This case includes a comparison among SBI, SVPWM-1 and SVPWM-2. Figures 11$a$ and $b$ describe the actual and reference speed trajectories for all inverters. SBI and SVPWM-2 are successfully tracked the speed-path with some oscillations. But, SVPWM-1 has some deviation through the path due to un-controlled dc-link input voltage. For enlarged stator currents shown in figure 
11-c, through deceleration as an example, there are some distortions for the waveforms of both SVPWM1 and -2 through speed transition from rated to 400 $\mathrm{rpm}$. But, the torque shown in figure 11-d, there are some deviation between the load and the motor internal torque for all types especially through starting and transition of deceleration. However, SBI in black colour, exerted more stable torque compared with other types, especially, SVPWM-1. This can be noticed from figures $11-\mathrm{e}$ and $\mathrm{f}$ that explore the dclink and stator line voltages for all types. SBI has a high value of the dc-link voltage compared to other types. This improves the performance of the motor through tracking of the predefined path.

\subsection{Case (3): Sinusoidal Reverse Rated-Speed Trajectory Low-Input Voltage (with a Comparison)}

In this case, the speed trajectory is a sinusoidal wave form with its peak value equal to the motor rated speed. The direction of rotation is reversed. The motor operates in the second quadrant mode to test the robustness of the proposed controller with another different speed trajectory. In addition, to test it against PV-parameter variation, the PV-terminal voltage was reduced to a minimum value. So, only one PV panel is connected in series with five in parallel to give approximately $54 \mathrm{~V}$ as input to the inverters. As shown in figure (12-a and b), SBI and SVPWM-2 are successfully tracked the path with a slight deviation. But SVPWM-1 couldn't track successfully the path, especially, through the rated speed. This can be clearly shown through the current profile shown in fig. 12c, the waveform is completely distorted but for others, the currents are sinusoidal. On the other hand, SBI demonstrates a good damping dynamic response through load changes shown in fig. 12d. Although the PV-input voltage was reduced but
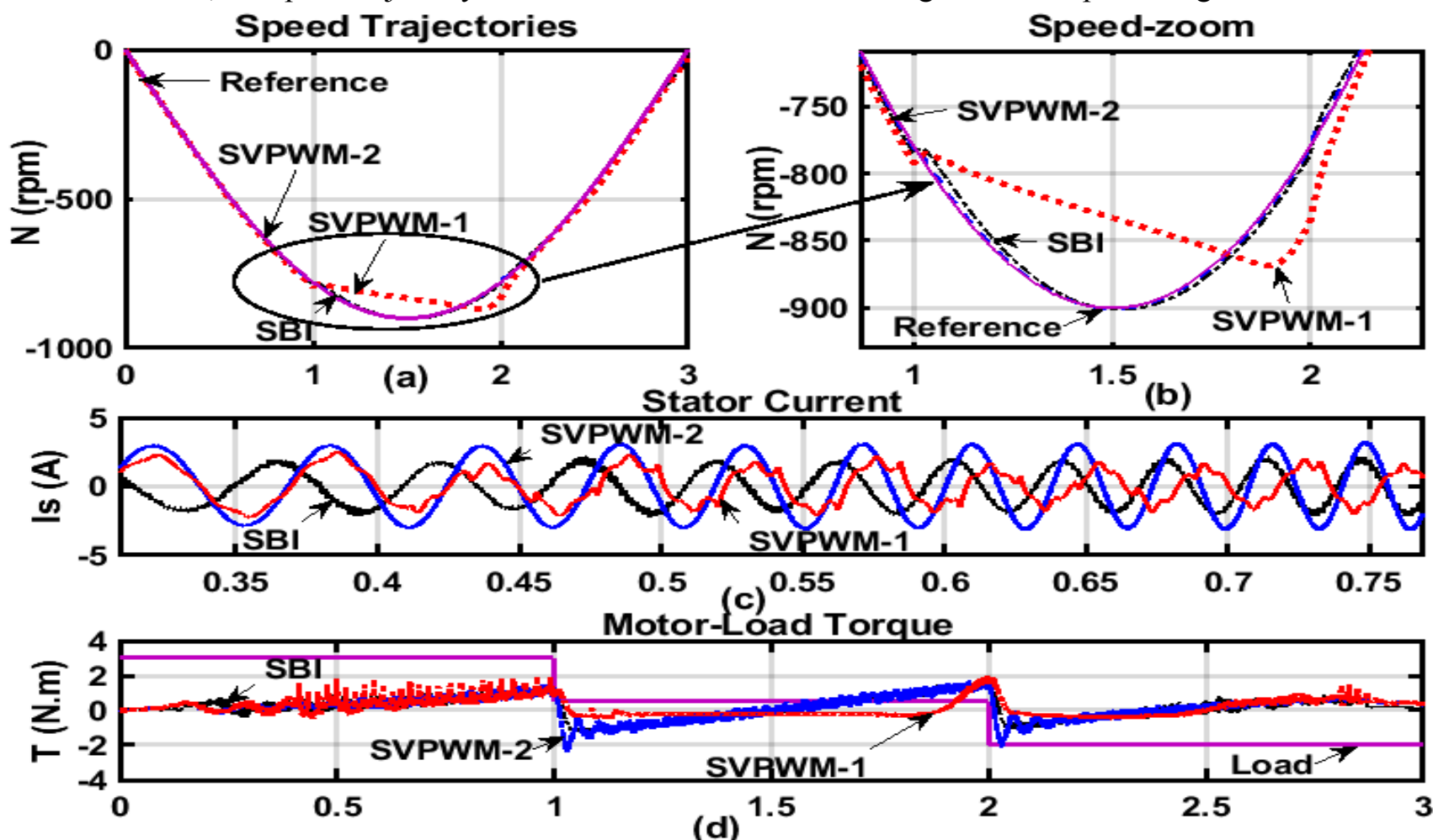

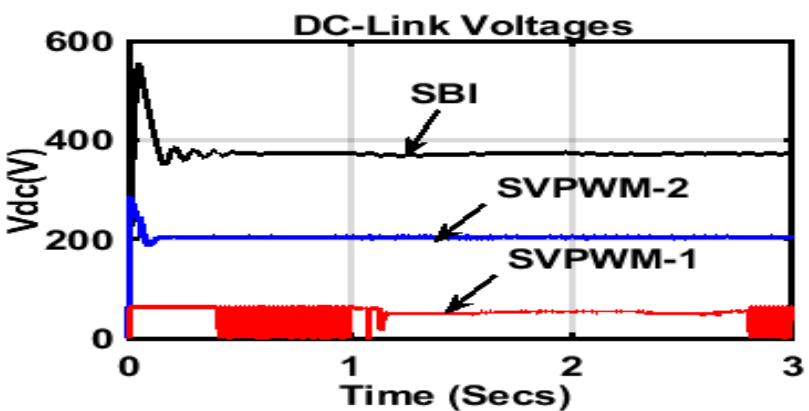

(e)

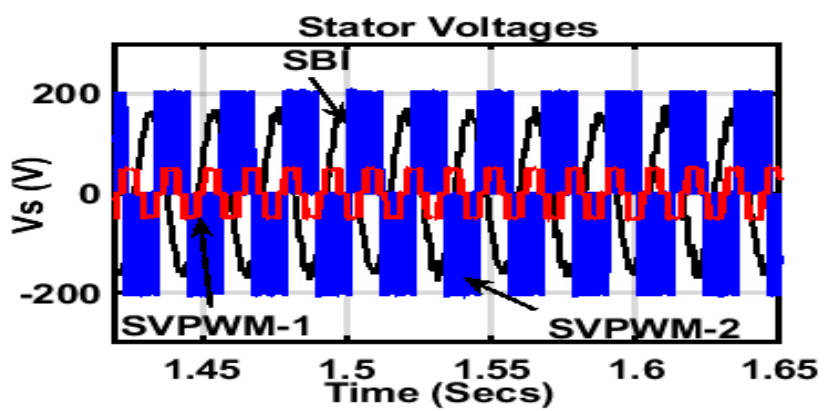

(f)

Fig. 12 Case 3: Low-input voltage for sinusoidal reverse-direction rated-speed trajectory (a comparison) (a) Speed (b) speed- enlargement (c) current (d) torque (e) dc-link voltage (f) stator input voltage 

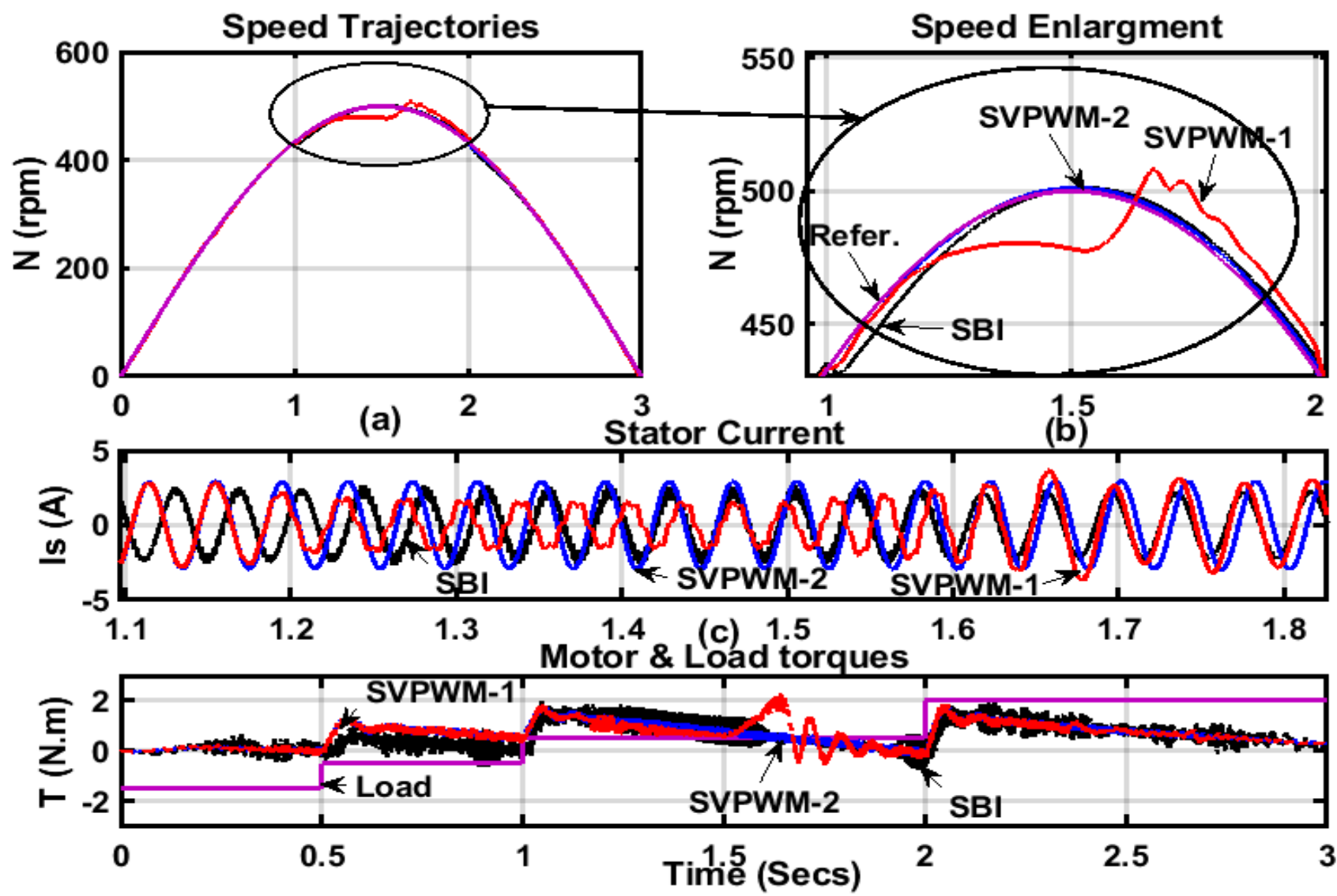

(d)

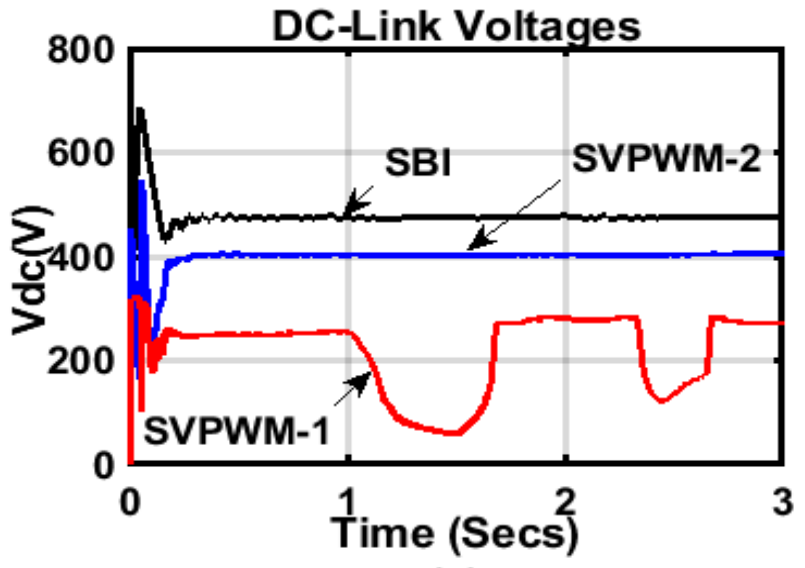

(e)

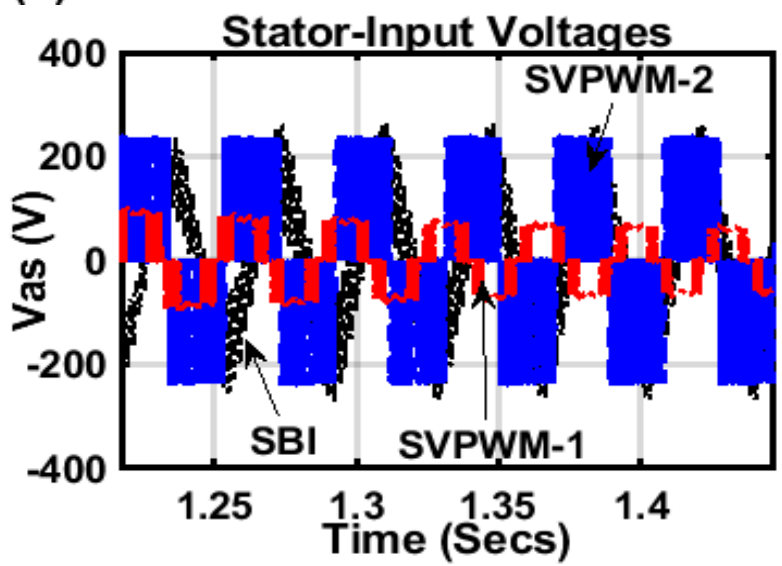

(f)

Fig. 13 Case 4: Low-speed for sinusoidal forward-direction trajectory (a comparison)

(a) Speed (b) speed-enlargement (c) current (d) torque (e) dc-link voltage (f) stator input voltage

the SBI- with the help of the proposed controller boosted it to approximately to $400 \mathrm{~V}$ (shown in fig. $12 \mathrm{e})$ that is sufficient to generate the AC-stator input voltage (shown in fig. 12f) needed for tracking control.

6.4. Case (4): Sinusoidal Forward Low-Speed Trajectory (with a Comparison)

In this case, the robustness of the controller is tested at very low speed for the motor. The proposed speed trajectory is a sinusoidal wave form with its peak value equal to $500 \mathrm{rpm}$. The direction of rotation is forward. Also, only 5 PV panels are connected in series to give approximately $270 \mathrm{~V}$ as input to the inverters. As shown in figure (13-a and b), SBI and SVPWM-2 are successfully tracked the path with a slight deviation. But SVPWM-1 couldn't track successfully the path, especially, through the top speed-curve. This can be clearly shown through the current profile, the waveform is completely distorted but for other type, the current is a sinusoidal. 
Also, the DC-link voltage of SBI is the greatest one as shown in figure $13 \mathrm{e}$ and dependently the homogeneity of the AC-voltage fed to the stator is shown in figure $13 \mathrm{f}$.

To test the SBI-output current waveforms homogeneity, Fourier fast transformation (FFT) is used to study the harmonics and compute the total harmonic distortion (THD). From the analysis (for ramp speed trajectory not included here), the THD for the current waveform of SBI $4.57 \%$ as shown in fig. 14. This value is low and within the standard IEEE range.

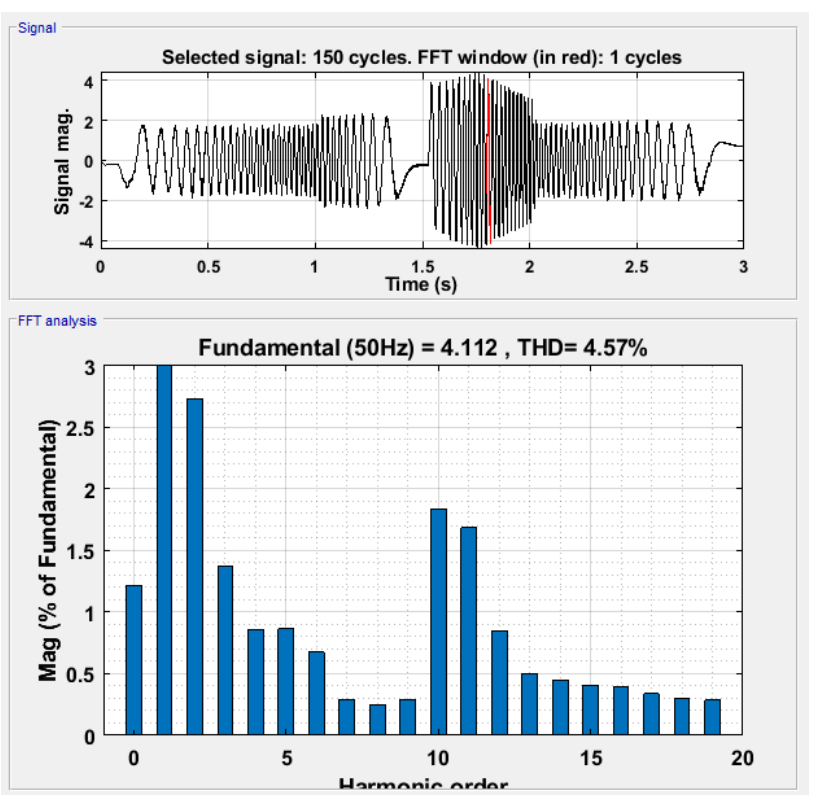

Fig. 14 THD for the stator current fed via SBI

\section{Conclusion}

This paper investigated the performance and behaviour of IM as a high performance when supplied from a modified PV-based nanogrid via a SBI. The IM served as a tracking system to follow some proposed prescribed random and homogenous speed trajectories. With the help of the proposed cruise speed control, the motor succeeded in following most tracks through using a scalar $(V / f)$ technique. The motor was operating with acceleration and deceleration modes in forward and reverse direction of rotation with rated and lower speeds. In addition, the proposed control made SBI robust against the transmitted intermittent renewable PV solar power to the motor in a sinusoidal waveform with balancing between achieving MPPT and dc-voltage stability. Although the PV- output voltage changes due to the irradiance variation, the proposed SBI-controller was able to boost the DClink voltage and dependently the AC-output voltage increased to produce the required tracking speed.
Furthermore, a combination of duty ratio (D) and modulation index (M) of SBI contributed to overcome the drawbacks of SBI. Two proposed controllers are used to modify both $\mathrm{D}$ and $\mathrm{M}$ to follow the path. The comparison between SBI, VSI-based SVPWM-1 and -2 are conducted to explore the validity of the proposed system in tracking. SBI has many features such as no need for dead time circuits and single-stage inverter that produces both DC and AC simultaneously. In addition, it needs to a few numbers of passive elements. So, test results insure the validity of the SBI as a good in tracking systems.

\section{Appendix A}

STC Power $=305 \mathrm{~W}$, PTC power $=208.6 \mathrm{~W}$, Current at maximum Power $=5.58 \mathrm{~A}$, Voltage at maximum power $=54.7 \mathrm{~V}$, Short circuit current $=5.96 \mathrm{~A}$, Opencircuit voltage $=64.2 \mathrm{~V}$, Number of cells $=96$, Maximum system voltage $=600$.

\section{References:}

[1] F. I. Ahmed et al., "Robustness, simplification and time consumption reduction of on-line trained ANNcontroller fed IM-servo drive", IEEE Inter. Symposium on Ind. Electron., June 12-16, 2001, Pusan, Korea.

[2] F. I. Ahmed et al., "Neuro-controller for high performance IM drives in robots", IEEE, International Joint Conference on Neural Networks (IJCNN), Washington DC, July 15-19, 2001, USA, pp. 20822087.

[3] E. A. Ebrahim and N. Hammad, " Fault analysis of current-controlled PWM-inverter fed induction motor drives", Proceeding of the $7^{\text {th }}$ Int. Conf. on Properties and Applications of Dielectric Materials, June 1-5 2003, Nagoya, Japan, pp. 1065- 1070.

[4] E. A. Ebrahim, "A novel approach of adaptive neuroPI vector controller fed IM servo drives", Proceeding of the 2002 IEEE/RSJ Int. Conf. on Intelligent Robots and Systems EPFL, Lausanne, Switzerland, October 2002, pp. 2181-2186.

[5] R. Mishra et Al., "Investigation of transient performance of VSI-Fed IM drives using Volts/Hz and vector control techniques", 2012 IEEE 2nd International Conference on Power, Control and Embedded Systems, 17-19 Dec. 2012, Allahabad, India, pp. 39-43.

[6] R. Ramchand, et al., "Online Computation of Hysteresis Boundary for Constant Switching Frequency Current-Error Space-Vector-Based Hysteresis Controller for VSI-Fed IM Drives", IEEE Transactions on Power Electronics, Volume 27, Issue: 3, March 2012, pp. $1521-1529$.

[7] J. Peter et al., "Nearly Constant Switching Space Vector Based Hysteresis Controller for VSI Fed IM Drive", IEEE Transactions on Industry Applications, Volume 54, Issue 4, July-Aug. 2018, pp. 3360 - 3371. 
[8] E. A. Ebrahim, et al., “ A Novel Approach of a SingleInput Multi-Outputs Converter for a Modified DC Nano-grid Within an Open Energy Systems", Journal of Electrical Engineering (JEE), On-line Publication May 2018.

[9] P. Sriramalakshmi and V. Sreedev, "Modified PWM control methods of $\mathrm{Z}$ source inverter for drive applications", ARPN J. Eng. Appl. Sci., vol. 10, 2015, pp.6932-6943.

[10] M. Shen, et al. "Comparison of traditional inverters and Z-source inverter for fuel cell vehicles", IEEE Transaction on power electronics, vol. 2, 2007, pp.1453-1463.

[11] L. Chen and FZ. Peng, "Dead-Time Elimination for Voltage Source Inverter", IEEE Transactions on Power Electronics, Vol. 2, 23 Mar.2008, pp. 574 -580.

[12] F.Z. Peng, "Z-Source Inverter", IEEE Transactions on industry applications, vol. 2, Mar. 2003, pp. 504-510.

[13] Y. Huang, et al., " $Z$-Source Inverter for Residential Photovoltaic Systems", IEEE Transactions on Power Electronics, vol. 6, Nov 2006, pp. 1776-1782.

[14] J. Liu, J. Hu and L. Xu, "Dynamic Modelling and Analysis of Z - Source Converter- Derivation of AC Small Signal Model and Design-Oriented Analysis", IEEE Transactions on Power Electronics, vol. 5, Sep. 2007, pp. 1786-1796.

[15] MK. Nguyen, et al., "A Comparison between SinglePhase Quasi- Z Source and Quasi-Switched Boost Inverters", IEEE Transactions on Industrial Electronic, Vol. 62, Issue 10, Oct. 2015, pp. 6336-6344.

[16] Y. Zhou and W. Huang, "Single-Stage Boost Inverter with Coupled Inductor", IEEE Transactions on Power Electronics, Vol. 27, Issue 4, April 2012, pp. 1885-1893.

[17] R. Adda, et al., "A PWM Control Strategy for Switched Boost Inverter", IEEE Energy Conversion Congress and Exposition (ECCE), 17-22 Sep. 2011, Phoenix, AZ, USA, pp. 991-996.

[18] S. Mishra, R, et al., "Inverse Watkins-Johnson Topology-Based Inverter", IEEE Transactions on Power Electronics, Vol. 27, Issue 3, March 2012, pp. 1066-1070.

[19] R. Adda, et al., "Implementation and Control of Switched Boost Inverter for DC Nanogrid Applications", IEEE Energy Conversion Congress and Exposition (ECCE), 17-22 Sep. 2011, Phoenix, AZ, USA, pp. 3811-3818.

[20] V. Anusree and P. Saifunnisa, "Closed Loop Control of Switched Boost Inverter", IEEE International Conference on Electrical, Electronic, and Optimization Techniques (ICEEOT), 3-5 March 2016, Chennai, India , pp. 3040-3044.

[21] M. Alam, et al., "Switched Boost Inverter Applicable for Solar Photovoltaic System Based Micro-Grid", IEEE 2nd International Conference on Control, Instrumentation, Energy \& Communication (CIEC), 2830 Jan. 2016, Kolkata, India, pp. 422-426.

[22] S. I. Ganesan, et al., "Control Scheme for a Bidirectional Converter in a Self-Sustaining LowVoltage DC Nanogrid", IEEE Transactions on
Industrial Electronics, Vol. 62, Issue 10, Oct. 2015, pp. 6317-6326.

[23] R. E. Rose and Maheswaran K., "A switched boost inverter fed three-phase induction motor drive", Journal of Emerging Technology and Innovative Research (JETIR), Vol. 2, Issue 6, June 2015, pp. 1697-1702.

[24] J. Divya and B. Das, "Performance Evaluation of Switched Boost Inverter for Induction Machine Drive Application", International Journal of Engineering \& Science Research, Vol. 4, Issue 10, October 2014, pp. 703-710.

[25] C. Thammarat and D. Puangdownreong, "Design of Fractional Order PID Controller for Induction Motor Speed Control System by Cuckoo Search", International Journal of Circuits, Systems and Signal Processing, Volume 13, 2019, pp. 92-96.

[26] N. Djagarov, et. al., "Power Quality Investigation on a Ship's Power System", International Journal of Circuits, Systems and Signal Processing, Volume 13, 2019, pp. 494-500.

[27] R. Venkateswari and S. Sreejith "Factors influencing the efficiency of photovoltaic system", Renewable and Sustainable Energy Reviews, Vol. 101, 2019, pp.376394.

[28] E. A. Ebrahim, "Bacteria-Foraging Based-Control of High-Performance Railway Level- Crossing Safety Drives Fed from Photovoltaic Array", Journal of Electrical Systems and Information Technology (JESIT), Vol. 3, Issue 3, Dec. 2016, pp. 485-512.

[29] E. A. Ebrahim, “Ant-Colony Optimization Control of Brushless-DC Motor Driving a Hybrid Electric-Bike and Fed from Photovoltaic Generator", 2016 IEEE Congress on Evolutionary Computation (CEC), 24-29 July 2016, Vancouver, Canada, pp. 4221-4228.

[30] A. Acakpovi and E. B. Hagan, "Novel Photovoltaic Module Modelling using Matlab/Simulink", International Journal of Computer Applications, Volume 83 - No.16, December 2013, pp. 27-32.

[31] R. Adda et al., "Pulse Width Modulation of ThreePhase Switched Boost Inverter", 2013 IEEE Energy Conversion Congress and Exposition, 15-19 Sept. 2013, Denver, CO, USA, pp. 769- 774.

[32] O. El-baksawi, "Whale Optimization Algorithm for Maximum Power Point Tracker for Controlling Induction Motor Driven by Photovoltaic System", WSEAS Transactions on Power Systems, Volume 14, 2019, Art. \#9, pp. 70-78

[33] M. Masoum, et al., Theoretical and experimental analyses of photovoltaic systems with voltage and current-based maximum power-point tracking, IEEE Trans. Energy Convers., vol. 17, no. 4, Dec. 2002, pp. 514-522.

[34] N. A. Maged, et al., "Closed-loop control of a singlestage switched-boost inverter in modified DCinterconnected nanogrids", IET Journal of Engineering (JOE), Vol. 2020, Issue. 10, pp. 843-853

[35] https://sam.nrel.gov/

[36] O. Elkholi et al., "Novel approach for SVPWM of two-level inverter fed induction motor drive", (IJPEDS), Vol. 11, No. 4, December 2020, pp. 1750-1758.

Creative Commons Attribution License 4.0 (Attribution 4.0 International, CC BY 4.0)

This article is published under the terms of the Creative Commons Attribution License 4.0

https://creativecommons.org/licenses/by/4.0/deed.en_US 